\title{
Nanocomposites Based on Conducting Polymers and Functionalized Carbon Nanotubes with Different Dopants Obtained by Electropolymerization
}

\author{
Florina Branzoi ${ }^{*}$, Viorel Branzoi ${ }^{2}$ \\ ${ }^{1}$ Institute of Physical Chemistry "Ilie Murgulescu” 202 Splaiul Independenţei, Bucharest, Romania \\ ${ }^{2}$ Department of Applied Physical Chemistry and Electrochemistry, University Politehnica of Bucharest, \\ Bucharest, Romania \\ Email: ${ }^{*}$ fbrinzoi@chimfiz.icf.ro, iv branzoi@chim.upb.ro
}

Received 26 February 2014; revised 25 March 2014; accepted 15 April 2014

Copyright (C) 2014 by authors and Scientific Research Publishing Inc.

This work is licensed under the Creative Commons Attribution International License (CC BY). http://creativecommons.org/licenses/by/4.0/

\section{Open Access}

\begin{abstract}
Nanocomposite films based on poly (3,4-ethylenedioxy thiophene) (PEDOT), functionalized singlewalled carbon nanotubes and different dopants were studied. It was fabricated by a simple oxidative electropolymerization method. The dopant substances used were SDS (Sodium dodecyl sulfate) and tiron (1,2-Dihydroxybenzene-3,5-disulfonic acid disodium salt hydrate). These nanocomposite films were grown electrochemically from aqueous solutions such that constituents were deposited simultaneously onto substrate electrode. The synthetic, morphological and electrical properties of the nanocomposite films obtained were compared. Scanning electron microscopy (SEM) revealed that the composite films consisted of nanoporous networks of SWCNTS (single-walled carbon nanotubes) coated with polymeric film. Cyclic voltammetry (CV), electro-chemical impedance spectroscopy (EIS) and FT-IR spectroscopy demonstrated that these composite films had similar electrochemical response rates to pure polymeric films but a lower resistance and much improved mechanical integrity. The negatively charged functionalized carbon nanotubes (CNTSF) served as anionic dopant during the electropolymerization to synthesize polymer/CNTSF composite films. The specific electrochemical capacitance of the composite films is a significantly higher value than that for pure polymer films prepared similarly. Using these composite films, the modified electrodes with improved properties were obtained. (In this paper, for simplicity, the SWANTs-COOH group will be noted CNTsF which means functionalized carbon nanotubes.)
\end{abstract}

\footnotetext{
${ }^{*}$ Corresponding author.
} 


\section{Keywords}

\section{Nanocomposite Films, Functionalized Carbon Nanotubes, SEM, Capacitance, Real Impedance}

\section{Introduction}

As a result of the first report concerning the preparation of carbon nanotubes (CNTs)/polymer composite like that many efforts have been made to combine CNTs and polymers to produce functional composite materials with superior properties [1]-[4]. Apart from possible improvements in the mechanical and electrical properties of polymers, the formation of CNTs/polymer composites have been and still are explored as a promising approach for an effective incorporation of CNTs into practical devices [5]-[9]. Composite material based on the coupling of conducting organic polymers (CPs) and CNTs have shown that they possess properties of the individual components with a synergistic effect [9]. In this context, a special attention has been paid to the following CPs: polyaniline (PANI), polypyrrole (PPY), polythiophene (PTh) [10]-[13] etc. Among the numerous materials devised, development of the polythiophene derivative, polyethylenedioxythiophene (PEDOT), has shown significant promise for the challenge at hand [14].

The combination of CNTs with CPs offers an attractive route to reinforce the polymer as well as to introduce electronic properties based on morphological modification or electronic interaction between the two components [4]-[9] [15]-[18]. However, it is difficult to process CNTs and insoluble in most solvents. In order to broaden their applications, it is necessary to tailor their solubility properties. For this reason, in this study, SWCNTs (singlewalled carbon nanotubes) covalently functionalized with polycarboxylic acids, were used. The SWCNTs graft copolymer has excellent solubilities in water and some organic solvents and it also exhibits an order of magnitude increase in electrical conductivity. It was also demonstrated that SWCNTs-COOH (single walled carbon nanotubes functionalized with polycarboxylic acids) showed an improved sensor performance compared to unfunctionalized SWCNTs because polycarboxylic acid is an conductive organic compound in its own right. Additionally, the presence of numerous functional groups in SWCNTs-COOH means that there is potential for covalent immobilization of various big molecules and specially biomolecules.

The chemical functionalization of CNTs (carbon nanotubes) has been shown to increase their solubility in different solvents and facilitate their processing. It has also been demonstrated that the chemical functionalization affects the CNTs rope size and results in exfoliation into smaller bundles and individual nanotubes. These issues are especially important for the fabrication of high-performance composite materials. On the other hand, CNTs are considered to be the ideal reinforcing fibers due to their exceptional mechanical, electronic and thermal properties, low density and high aspect ratio. However, the incorporation of CNTs into the polymer matrix is often problematic due to the chemical inertness of CNTs. The covalent functionalization of CNTs is a valuable route towards the development of high-performance composites. It provides homogeneously dispersed CNTs incorporated in the polymer and a strong interfacial bonding between the polymer and CNTs. We have applied chemically functionalized SWNTs-COOH to prepare a number of SWNT-polymer composite materials. CNTs can be divided into two main categories: single-walled carbon nanotubes (SWNTs) and multi-walled carbon nanotubes (MWNTs). The first are formed by a single graphene sheet. The latter are formed by additional graphene sheets wrapped around the SWNT core. As a result of the first report concerning the preparation of a CNTs/polymer composite by Ajayan et al., many efforts have been made to combine CNTs and polymers to produce functional composite materials with superior properties. Apart from possible improvements in the mechanical and electrical properties of polymers, the formation of CNTs/polymer composites has been and still is explored as a promising approach for an effective incorporation of CNTs into practical devices [18]-[26].

In this study is described electrochemical synthesis of nanocomposite films from conducting polymers and functionalized single-walled carbon nanotubes (FSWCNTs) with different dopants and electrochemical characterization of these nanocomposites by cyclic voltammetry, electrochemical impedance spectroscopy, FT-IR and scanning electron microscopy (SEM), have been presented in this paper.

\section{Experimental}

The electrochemical polymerizations were carried out using a conventional three electrodes system. A platinum 
electrode and a saturated calomel electrode (SCE) were used as counter and reference electrode, respectively. The reference electrode was placed in a separate cell and was connected to the electrolytic cell via a salt bridge that ends as a Luggin capillary in the electrolytic cell. This arrangement helps in reducing the ohmic resistance of the electrochemical system. The working electrode was made from a platinum disk with surface area of 0.5 $\mathrm{cm}^{2}$. In this study were used single-walled carbon nanotubes functionalized with carboxylic acid (FSWCNTs) were provided by CarbonSolutions, Inc. (www.carbonsolution.com, Riverside, CA), and 3,4-ethylenedioxy thiophene (EDOT) (99.5\% Fluka) was used as supplied. Which were purchased from Sigma-Aldrich with the following characteristics: $80 \%-90 \%$ carbon basis, D $\times$ L $2-10 \mathrm{~nm} \times 0.5-2 \mu \mathrm{m}$, bundle dimensions. The organic carboxyl groups formed on a nanotube surface are localized at the defects in functionalized single-walled and suitable reactive organic groups from other chemical chains are prone to react in this zone. Bidistilled water was used for all sample preparations. All chemicals were of the highest quality commercially available and were used as received. Cyclic voltammetry and electrochemical impedance spectroscopy were used to investigate the electrochemical properties of the composite films. Electrochemical experiments were carried out with an automated model VoltaLab 40 potentiostat/galvanostat with EIS dynamic controlled by a personal computer. All the following potentials reported in this work are against the SCE (saturated calomel electrode). Scanning electron microscopy (SEM) was used to compare the microstructures of the deposited films.

\subsection{Preparation of Modified Electrodes}

The Pt electrode was carefully polished with aqueous slurries of fine alumina powder 0.05 micron on a polishing cloth until a mirror finish was obtained. After 20 min sonication, the electrodes were immersed in concentrated $\mathrm{H}_{2} \mathrm{SO}_{4}$, followed by thorough rinsing with water and ethanol. The prepared electrodes were dried and used for modification immediately. Nanocomposite films of CPs/FSWCNTs were prepared by electrochemical polymerization from a solution containing both the functionalized carbon nanotubes (FSWCNTs) and the corresponding monomer (2,3-dioxythiophene). One kind of FSWCNTs was used in this work namely: single wall carbon nanotubes (SWCNTs with carboxylic acids, see Scheme 1). In the first step, the FSWCNTs aqueous suspension (usually $10 \mathrm{mg} / \mathrm{L}$ ) was prepared via sonication $(1 \mathrm{~h}$ ) and then the synthesis solution was prepared straightaway by dissolving the monomer and the corresponding supporting electrolyte in the FSWCNTs aqueous suspension. The negatively charged FSWCNTs in solution acted as sole supporting electrolyte and dopant for the (3,4-ethylenedioxy thiophene)-EDOT depositions. For this reason FSWCNTs are enwrapped in polymers during the electropolymerization process in the form of counter ions or dopants. Thus, PEDOT-FSWCNTs composite films were prepared, from an aqueous solution containing $0.025 \mathrm{~mol} / \mathrm{L}$ of 2,3-dioxythiophene $+0.1 \mathrm{M}$ of $\mathrm{LiClO}_{4}+10$ $\mathrm{mg} / \mathrm{L}$ of FSWCNTs by cyclic voltammetry in the potential scanning range of $0 \mathrm{mV}$ to $+1250 \mathrm{mV}$ at a scan rate of $10 \mathrm{mV} / \mathrm{s}$ and for a cycles number of 10 . The pure poly (3,4-ethylenedioxy thiophene) films were prepared from an aqueous solution of $0.025 \mathrm{~mol} / \mathrm{L} \mathrm{2,3-dioxythiophene}+0.1 \mathrm{M} \mathrm{LiClO}_{4}$, without adding FSWCNTs, also by cyclic voltammetry in the potential range $0 \mathrm{mV}$ to $+1250 \mathrm{mV}$ at a scan rate of $10 \mathrm{mV} / \mathrm{s}$.

\subsection{Characterization of the Modified Electrodes}

Electrochemical impedance spectroscopy (EIS) and cyclic voltammetry (CV) were used to investigate the electrochemical properties of the composite films. The electrochemical characterization of the PEDOT-FSWCNTs and PEDOT films was carried out in $0.1 \mathrm{M} \mathrm{LiClO}_{4}$ cycling aqueous solutions for comparison and because the dopant anion of the polymeric films is the same with the anion of the cycling solution. The working electrode potential was cycled in the potential range of $0 \mathrm{mV}$ to $+1250 \mathrm{mV}$ with a scan rate of $50 \mathrm{mV} / \mathrm{s}$. The impedance measurements were performed using a VoltaLab 40 potentiostat/galvanostat with EIS dynamic in the frequency range of $100 \mathrm{kHz}$ to $1 \mathrm{mHz}$ with an AC wave of $5 \mathrm{mV}$ (peak-to-peak) overlaid on a DC bias potential and the impedance data were obtained at a rate of 10 points per decade change in frequency. All tests have been performed at $25^{\circ} \mathrm{C}$ under atmospheric oxygen without agitation.

\section{Results and Discussions}

The PEDOT film was obtained on the platinum substrate in a synthesis solution of $0.025 \mathrm{~mol} / \mathrm{L} 2,3-$ dioxythiophene $+0.1 \mathrm{M} \mathrm{LiClO}_{4}$ by cyclic voltammetry in the scanning potential range of 0 to $+1250 \mathrm{mV}$ at a scan rate of $10 \mathrm{mV} / \mathrm{s}$ and for 10 cycles. It is clearly seen from Figure 1 that, the reaction current increases 


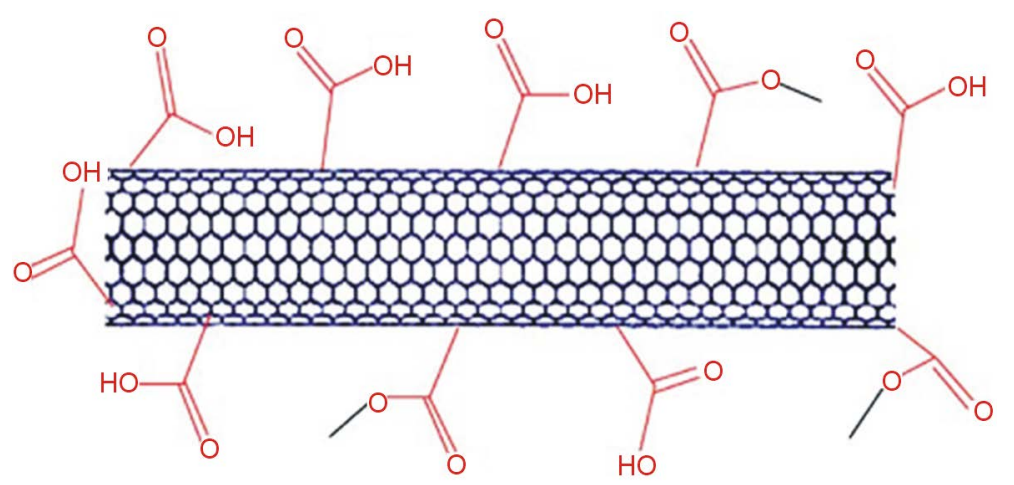

Scheme 1. Chemical structure of single walled carbon nanotube functionalized with carboxylic acids (SWCNTs-COOH).

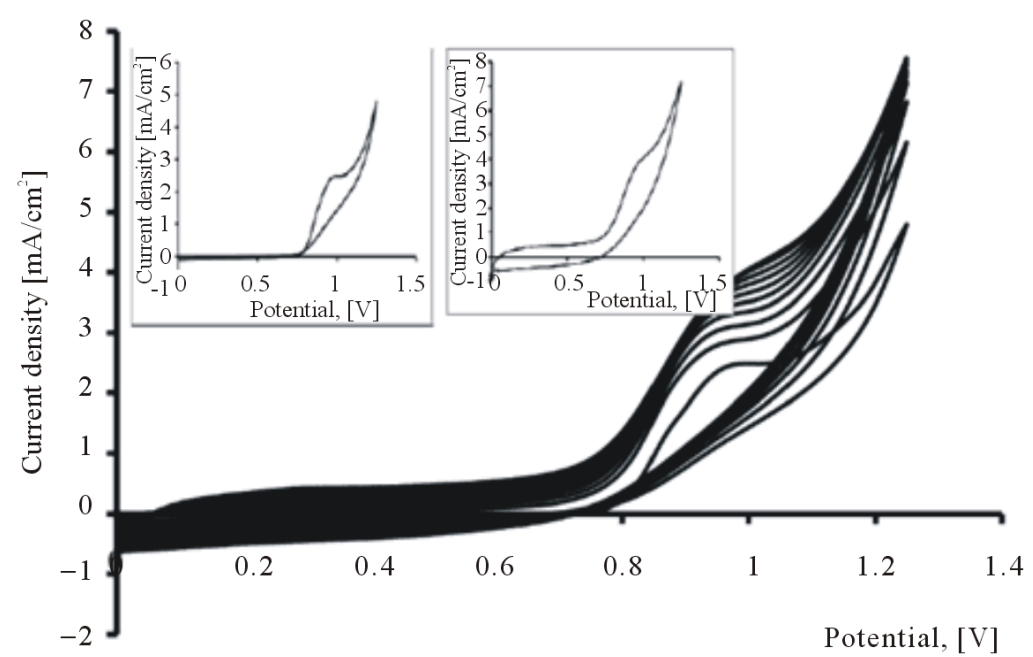

(a)

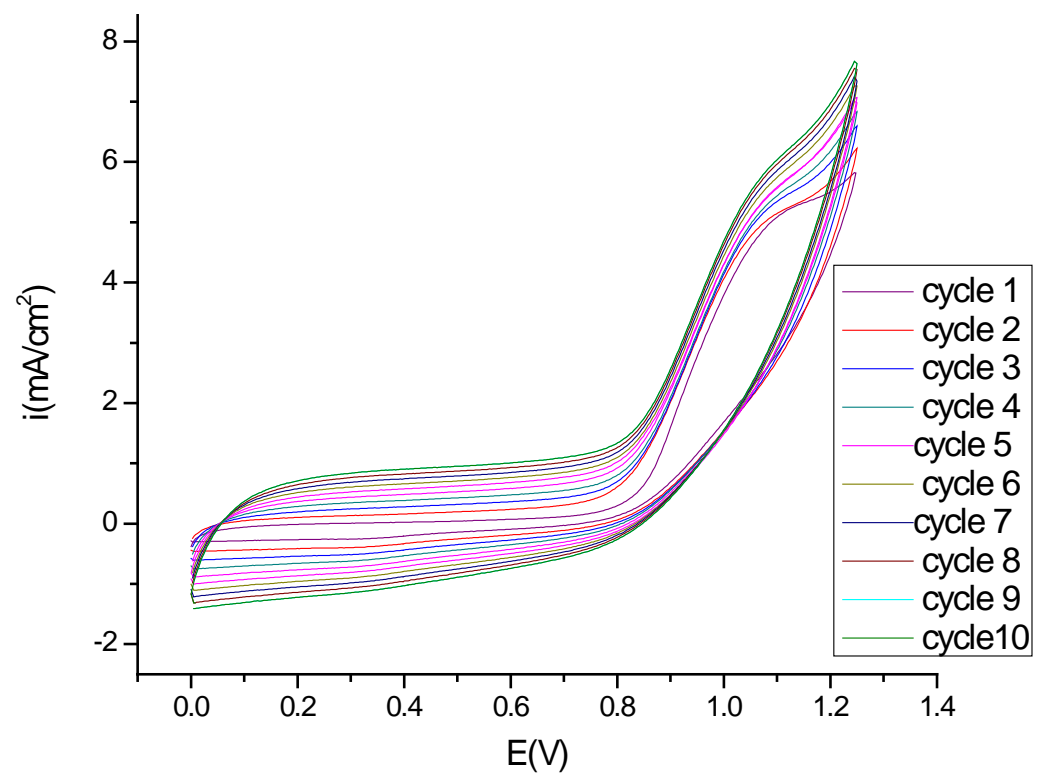

(b)

Figure 1. Polymerization cyclovoltammograms of 2,3-dioxythiophene in $0.1 \mathrm{M}$ $\mathrm{LiClO}_{4}$ aqueous solution. Inset $1^{\text {st }}$ Cycle (a) and $10^{\text {th }}$ Cycle (b). 
sharply when the applied potential is larger than $0.7 \mathrm{~V}$, which reveals the formation of the radical cations. The increased current implies that the EDOT radical cations start to electropolymerize onto the platinum electrode. During the first potential scan, the polymerization potential of PEDOT on Pt is around $0.975 \mathrm{~V}$, while the onset of polymerization shifts significantly on following scans to more positive potentials and stabilizes at $1.095 \mathrm{~V}$.

Composite films of poly (3,4-ethylenedioxythiophene) and functionalized, single-walled carbon nanotubes (PEDOT-FSWCNTs) were fabricated by a simple oxidative electropolymerization method. These films were electrodeposited on a platinum working electrode using a classical system with three electrodes. The PEDOT/ CNT-COOH film was obtained on the platinum substrate in a synthesis solution of $0.025 \mathrm{~mol} / \mathrm{L}$ 2,3-dioxythiophene $+10 \mathrm{mg} / \mathrm{L}$ carbon nanotubes polycarboxylic acids.

The obtained cyclovoltammograms are given in Figure 2 and have the same shapes with those obtained for PEDOT/Pt modified electrode cycled in the same conditions, but in this case the anodic peaks are much higher and larger than those for PEDOT film. This fact can be explained taking into account that, FSWCNTs (in our case SWCNTs-COOH) are negatively charged and they can act as doped anions and consequently, the conductivity of PEDOT/FSWCNTs composite film increases.

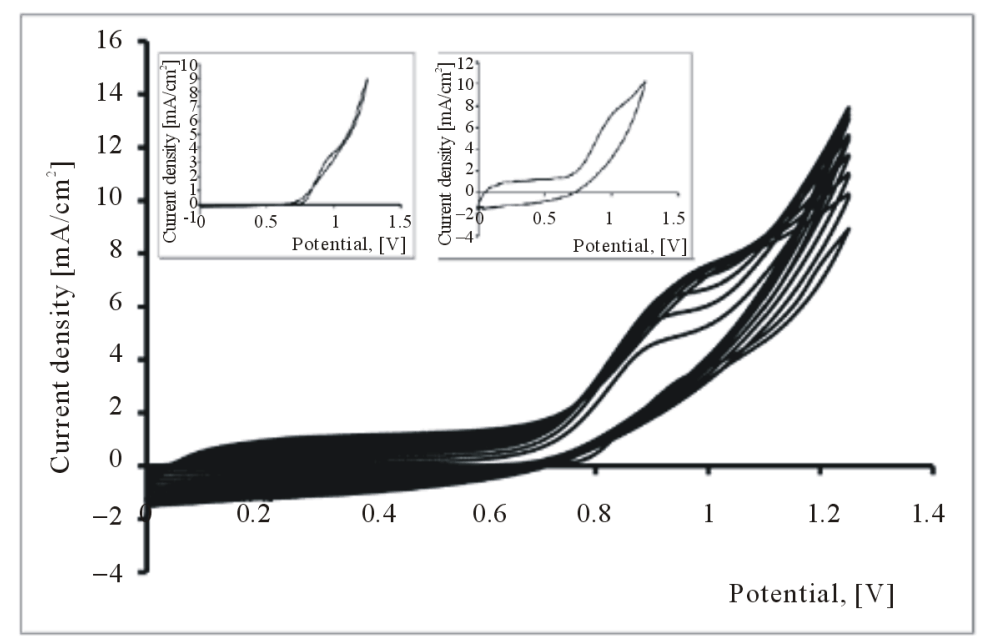

(a)

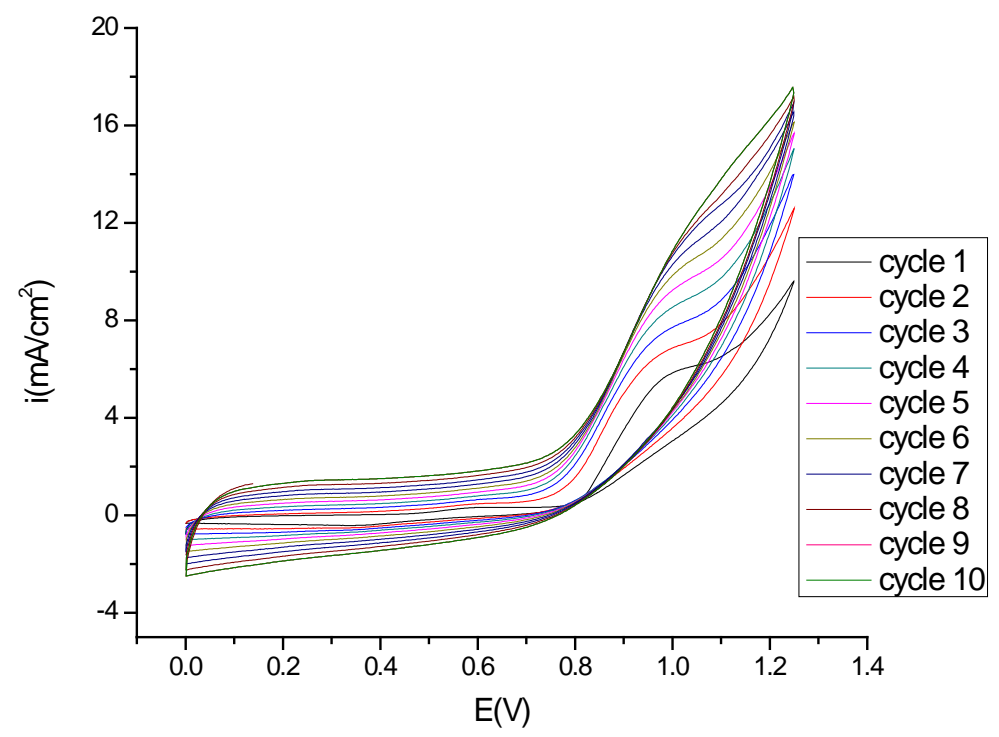

(b)

Figure 2. Polymerization cyclovoltammograms of 2,3-dioxythiophene CNT-COOH in $0.1 \mathrm{M} \mathrm{LiClO}_{4}$ aqueous. solution. Inset $1^{\text {st }}$ Cycle (a) and $10^{\text {th }}$ Cycle (b). 
Hence, the PEDOT/FSWCNTs composites exibit higher currents than PEDOT films, which can be translated into larger capacitance. This is an indication of faster kinetics in the composite, which can be attributed to the higher electronic conductivity of the FSWCNTs network. This means that the redox processes which take place in nanocomposite film are more intense and more complex than those in the pure PEDOT film.

The PEDOT/CNT-COOH/dopant films were obtained on the platinum substrate in a synthesis solution of $0.025 \mathrm{~mol} / \mathrm{L} \mathrm{2,3-dioxythiophene}+10 \mathrm{mg} / \mathrm{L} \mathrm{CNT}-\mathrm{COOH}+0.01 \mathrm{~mol} / \mathrm{L}$ dopant substance in $0.1 \mathrm{M} \mathrm{LiClO}_{4}$ by cyclic voltammetry in the scanning potential range of 0 to $+1250 \mathrm{mV}$ at a scan rate of $10 \mathrm{mV} / \mathrm{s}$ and for 10 cycles. The dopant substances used were SDS (Sodium dodecyl sulfate) and tiron (1,2-Dihydroxybenzene-3,5-disulfonic acid disodium salt hydrate). In the presence of dopant (SDS and tiron, see Figure 3), it is observed that the current response of doped PEDOT films decreases with addition of the dopant. Moreover, the current increases with continuous cycling in the potential range as seen in Figure 3. During the first potential scan, the polymerization potential of PEDOT/CNT-COOH/dopant on Pt is around $1.05 \mathrm{~V}$, while the onset of polymerization shifts significantly on following scans to more positive potentials and stabilizes at $1.10 \mathrm{~V}$. All PEDOT composite films were uniform, smooth and adherent to the surface of Pt electrode.

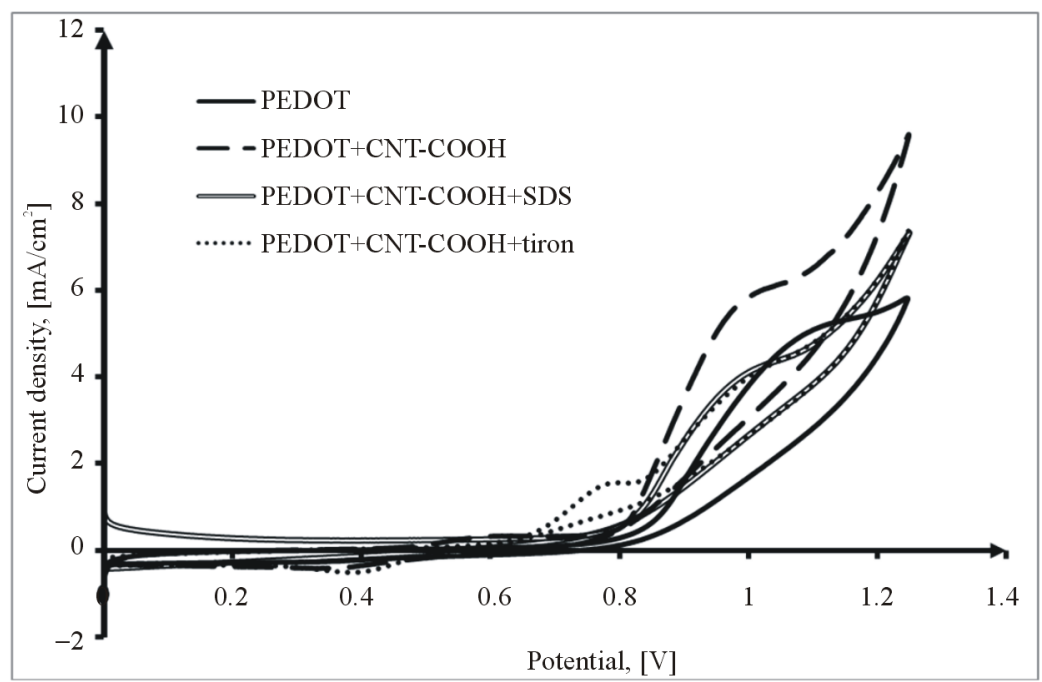

(a)

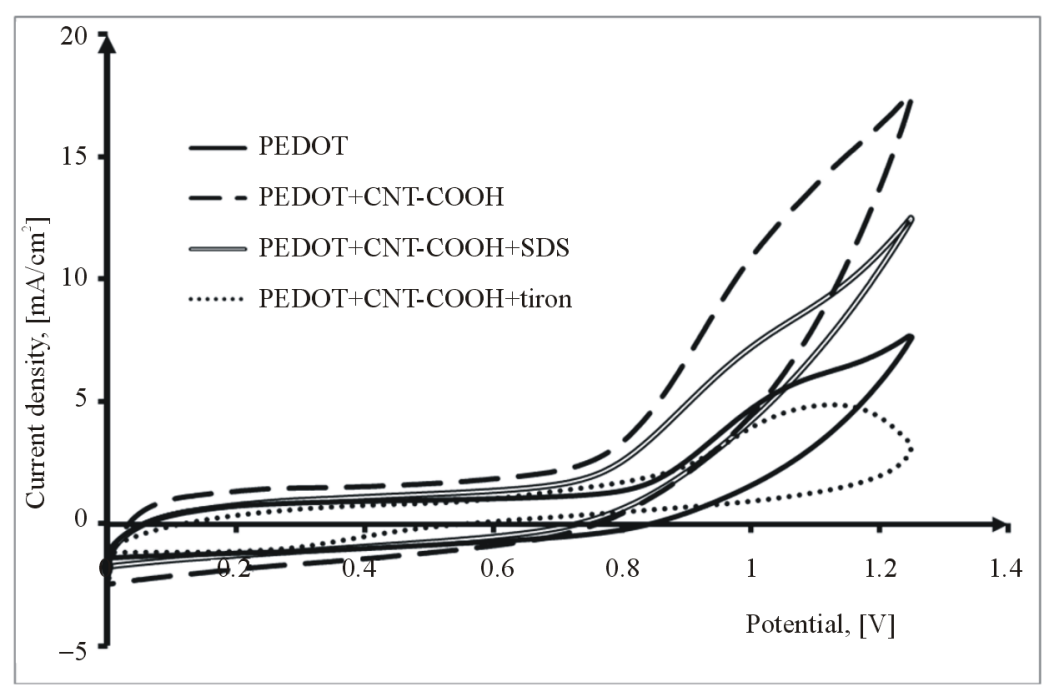

(b)

Figure 3. Comparative polymerization cyclovoltammograms of 2,3-dioxythiophene + CNT-COOH + dopat in $0.1 \mathrm{M} \mathrm{LiClO}_{4}$ aqueous solution, $1^{\text {st }}$ Cycle (a) and $10^{\text {th }}$ Cycle (b). 
The electrochemical behavior of the PEDOT, PEDOT/CNT-COOH films deposited electrochemically from aqueous solution in the absence and presence of dopant (SDS and tiron) was characterized further using cyclic voltammetry. The electrochemical characteristics of obtained PEDOT film was study in the cycling solutions, an aqueous solution of $0.1 \mathrm{M} \mathrm{LiClO}_{4}$. The electrode potential was cycled on the potential range from 0 up to 1250 $\mathrm{mV}$ with a sweep rate of $50 \mathrm{mV} / \mathrm{s}$ and for a cycles number of 20 (see Figure 4).

The electrochemical characteristics of obtained PEDOT/CNT-COOH film was study in the cycling solutions, an aqueous solution of $0.1 \mathrm{M} \mathrm{LiClO}_{4}$. The electrode potential was cycled on the potential range from 0 up to $1250 \mathrm{mV}$ with a sweep rate of $50 \mathrm{mV} / \mathrm{s}$ and for a cycles number of 20 (see Figure 5). These films can be cycled repeatedly between the conducting (oxidized) and insulating (neutral) state without significant decomposition of the material, which is consistent with the results reported in the literature [17].

As can be seen, the curves of these polymer films have nearly rectangular shape, which is typical of the pure capacitive behavior of the tested object [21]-[31]. However, the current of film obtained by potentiodynamic method in presence of dopant is nearly 3 times of the film gained in absence of dopant.

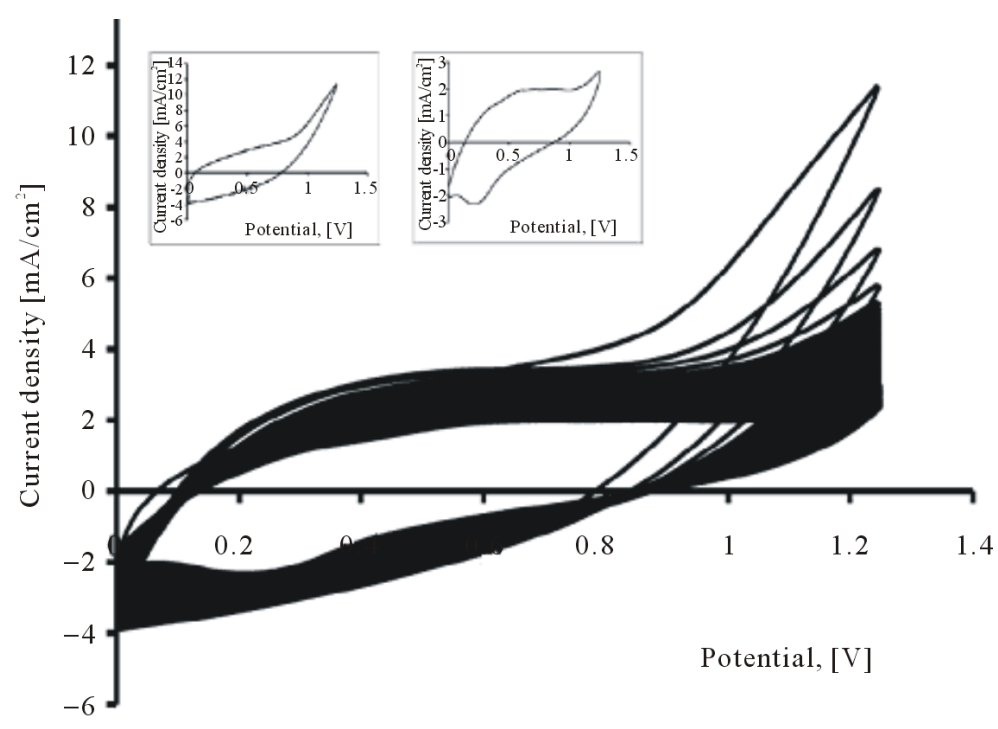

(a)

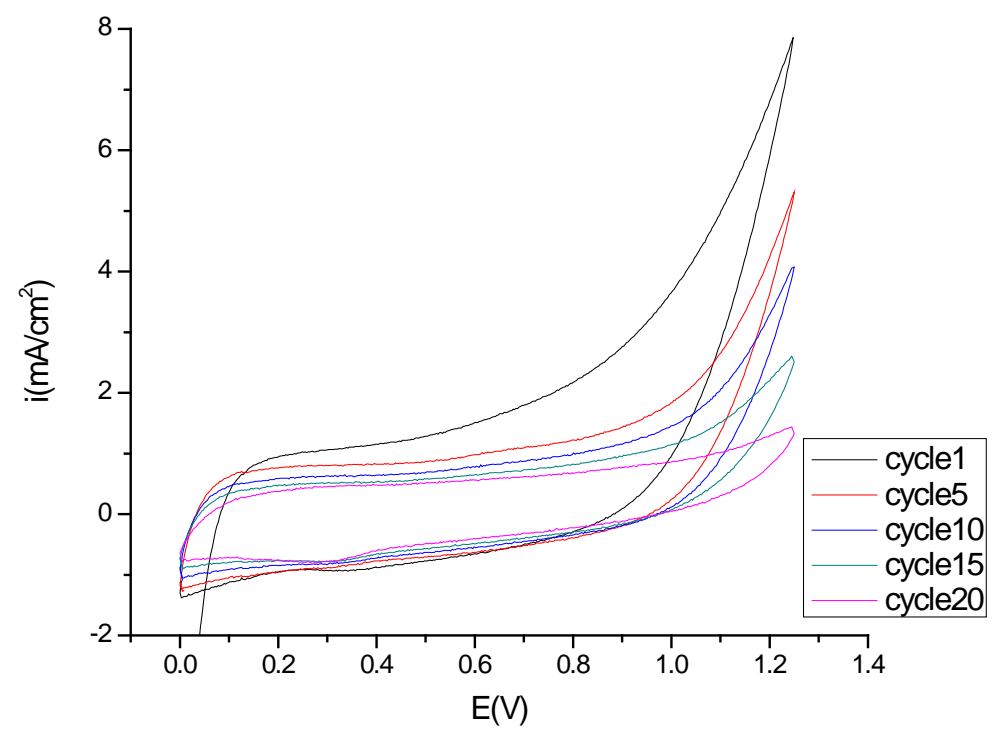

(b)

Figure 4. Cyclic voltammograms of PEDOT film in cycling solution (monomer free) of $0.1 \mathrm{M} \mathrm{LiClO}_{4}$. Inset $1^{\text {st }}$ Cycle (a) and $50^{\text {th }}$ Cycle (b). 


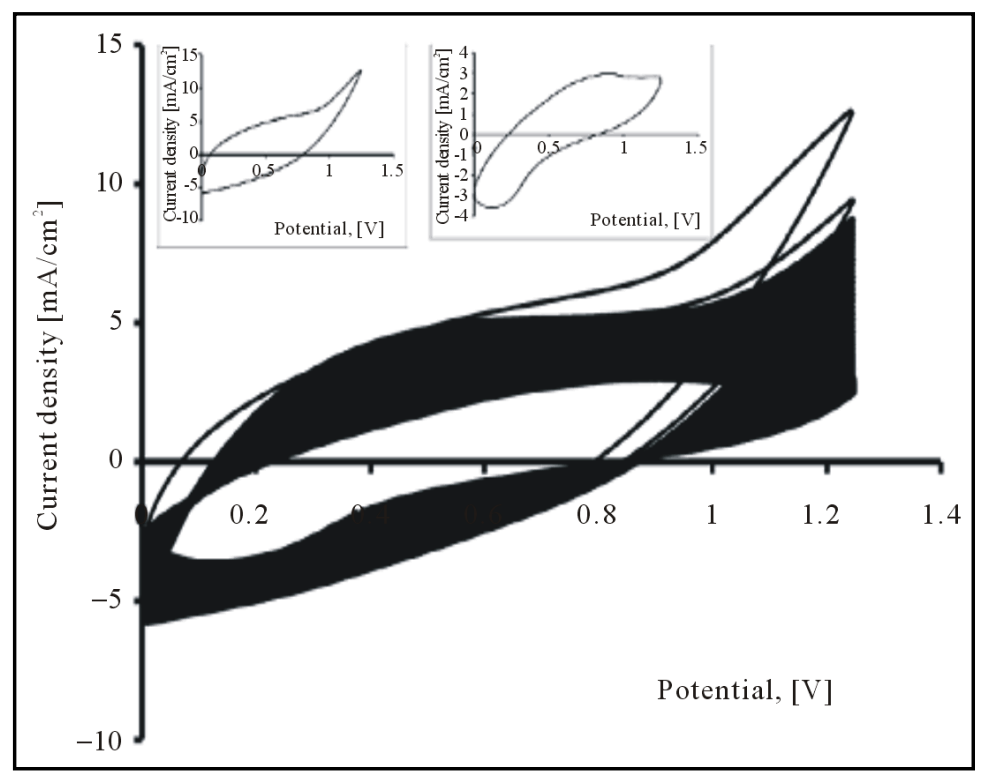

(a)

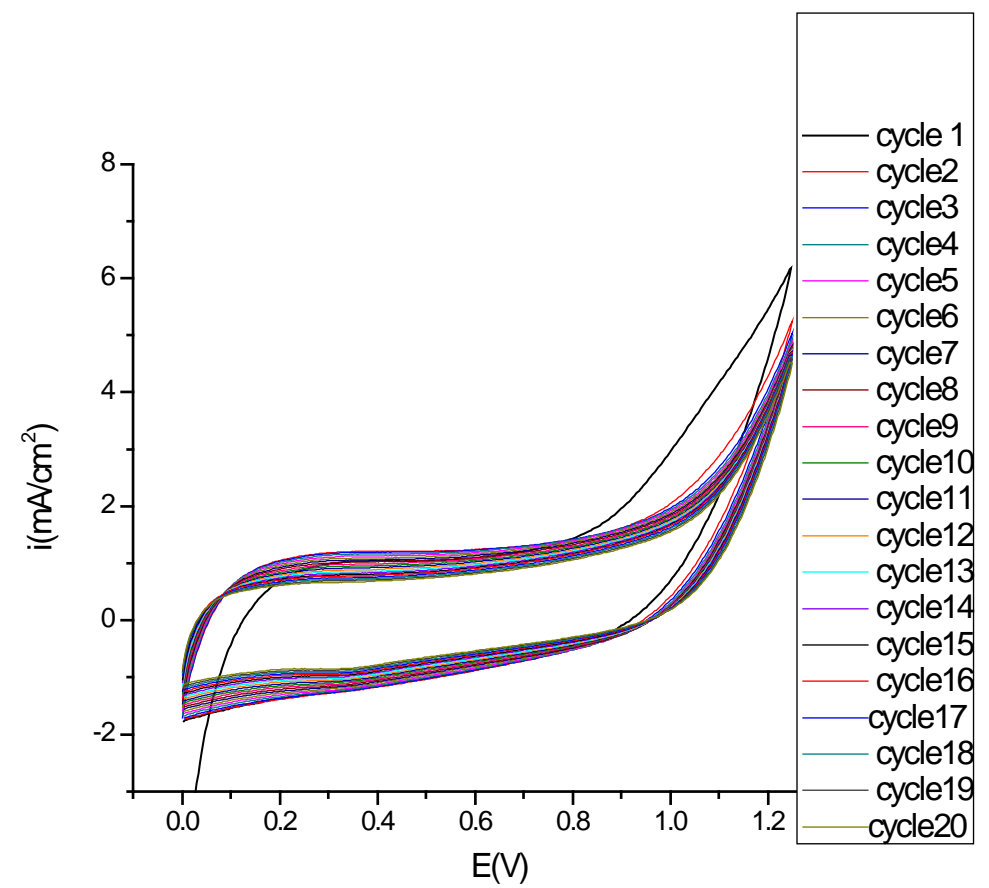

(b)

Figure 5. Cyclic voltammograms of PEDOT/CNT-COOH film in cycling solution (monomer free) of $0.1 \mathrm{M} \mathrm{LiClO}_{4}$. Inset $1^{\text {st }}$ Cycle (a) and $50^{\text {th }}$ Cycle (b).

The electrochemical characteristics of obtained PEDOT and PEDOT/CNT-COOH/dopant films were study in the cycling solution, an aqueous solution of $0.1 \mathrm{M} \mathrm{LiClO}_{4}$. The electrode potential was cycled on the potential range from 0 up to $1250 \mathrm{mV}$ with a sweep rate of $50 \mathrm{mV} / \mathrm{s}$ and for a cycles number of 20 (see Figure 6).

Analyzing in comparison the obtained results it can be observed that, in all the cases the PEDOT/CNT-COOH composite film reveals current much higher than PEDOT film. This fact can be explained thus, the PEDOT chains became neutral and the negative charge of immobile FCNTSF should be balanced by the cations with small size from the supporting electrolyte solution. 


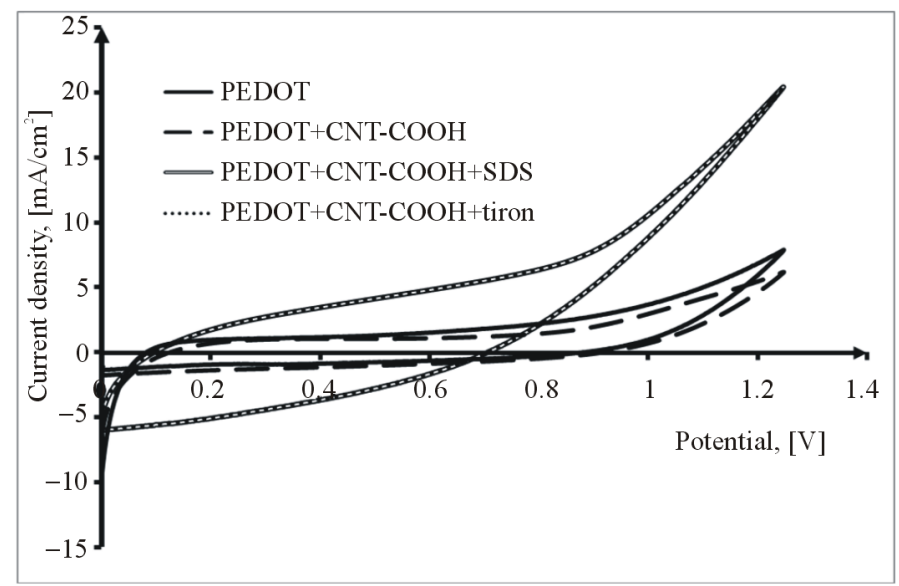

(a)

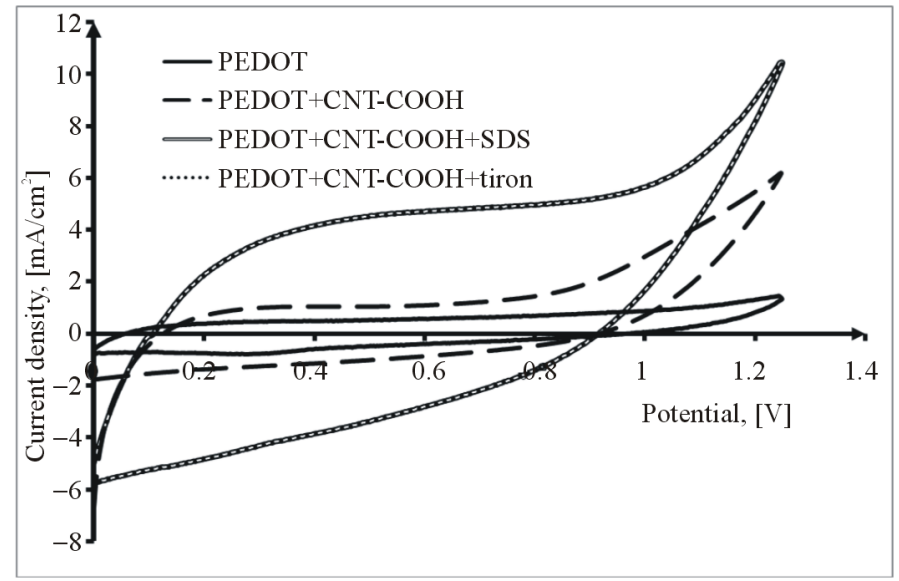

(b)

Figure 6. Comparative cyclic voltammograms of PEDOT, PEDOT/ CNT-COOH with dopants films in cycling solution (monomer free) of $0.1 \mathrm{M} \mathrm{LiClO}_{4}, 1^{\text {st }}$ Cycle (a) and $20^{\text {th }}$ Cycle (b).

The surface morphology, formation mechanism and electrochemical nature of PEDOT-FSWCNTs films were investigated using scanning electron microscopy (SEM), cyclic voltammetry (CV) and alternating current (AC) impedance spectroscopy (EIS). CV (cyclic voltammetry) and EIS (electrochemical impedance spectroscopy) revealed that the PEDOT-FSWCNTs electrode had higher electrocatalytic activity for the redox reaction and a smaller charge transfer resistance than the PEDOT electrodes.

Further, the composite and pure polymer films were studied by EIS at open circuit potential, in an aqueous solution of $0.1 \mathrm{M} \mathrm{LiClO}_{4}$ and $25^{\circ} \mathrm{C}$. The resulting Nyquist plots and Bode plots for PEDOT, PEDOT/SWCNTs$\mathrm{COOH}$ and PEDOT/SWCNTs-COOH/dopant systems are shown in Figure 7 and Figure 8. The impedance plot is composed of a semicircle at high frequencies and a capacitive slope at low and middle frequencies (see Figure 7 and Figure 8). The semicircle appeared at high frequencies is considered to owe to the charge transfer resistance, which originates from the interface structure between the porous electrode surface and the electrolyte [19]. At low frequencies, the impedance plot becomes a near vertical line. The Nyquist plots for both PEDOT, PEDOT/SWCNTs-COOH and PEDOT/SWCNTs-COOH/dopant composite films are featured by a vertical trend at low frequencies, indicating a capacitive behaviour according to the equivalent circuit theory. Bode diagrams point out also the capacitive behaviour in concordance with Nyquist plots (see in comparison Figures 7(a)-(d) and Figures 8(a)-(d)).

The capacitances of the electrode materials were calculated, according to the equation:

$$
C=-1 /\left(2 \pi f Z_{\text {im }}\right) \text {. }
$$




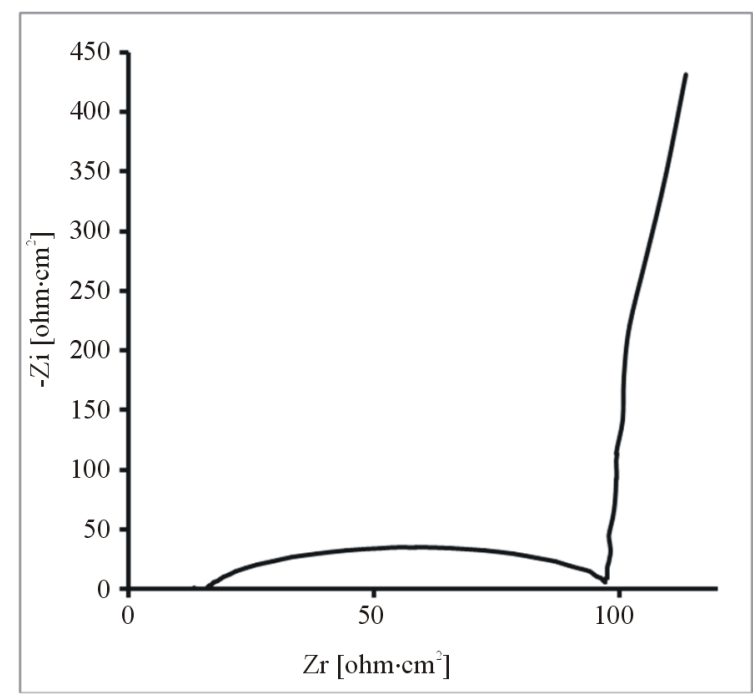

(a)

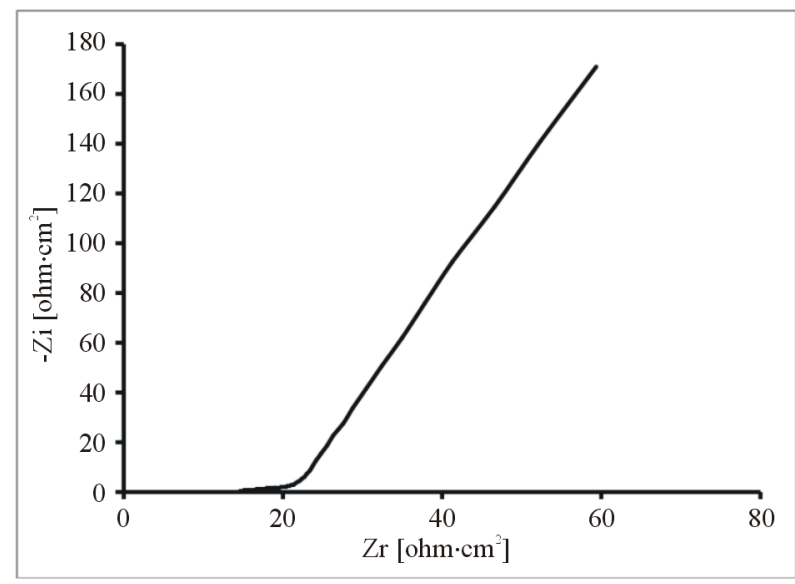

(c)

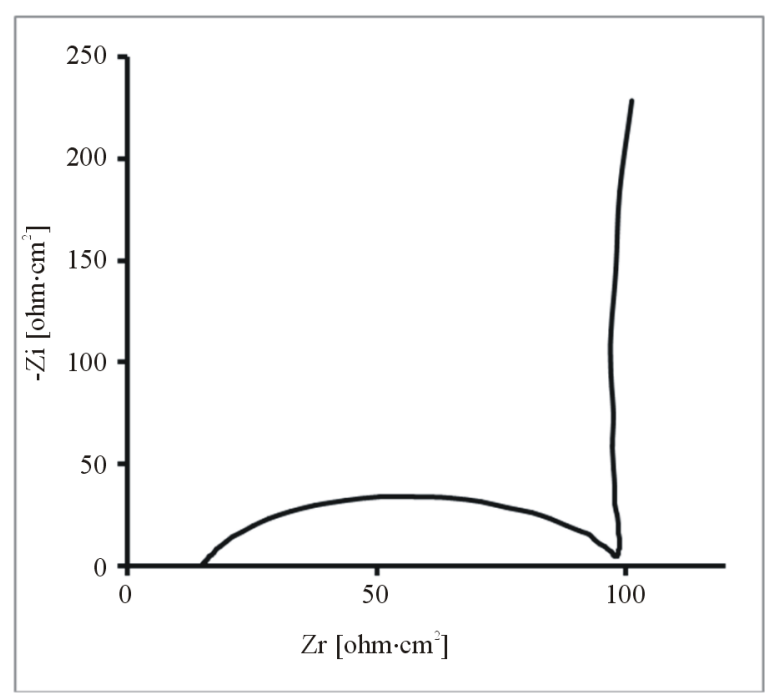

(b)

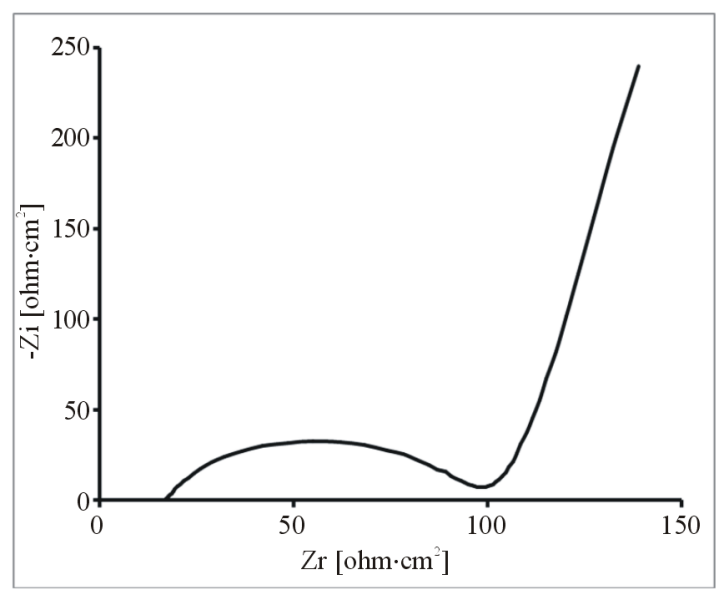

(d)

Figure 7. The Nyquist diagrams for modified electrodes (a) PEDOT/Pt, (b) PEDOT/CNsT-COOH/Pt, (c) PEDOT/CNTs$\mathrm{COOH} / \mathrm{SDS} / \mathrm{Pt}$ and (d) PEDOT/CNTs-COOH/tiron/Pt at open circuit potential in an aqueous solution of $0.1 \mathrm{M} \mathrm{LiClO}_{4}$.

( $f$ = frequency; $\mathrm{Z}_{\mathrm{im}}=$ imaginary impedance), from the slope of the linear correlation between the imaginary impedance and the reciprocal of the frequency at low frequencies.

From these Figures 7-9 and Table 1, one can observe higher capacitance the one order of magnitude value for PEDOT/FSWCNTs + dopant film in respect with PEDOT pure polymeric films. Higher capacitance of the composite films results obviously from the contribution of the embedded FSWCNTs that provide interconnected pathways for electrons through the FSWCNTs and ions through the pore network or the direct interaction between the delocalised electrons on polymer chains and the FSWCNTs.

The real impedance at low frequencies, where the capacitive behaviour dominates, is an indication of the combined resistance of the electrolyte and the film including both electronic and ionic contributions. The values of the real impedance at $0.01 \mathrm{~Hz}$ are given also in Table 1 . It can be seen that the PEDOT/FSWCNTs films were significantly lower in resistance than PEDOT films. It can also be seen that PEDOT/FSWCNTs offered much higher overall conductivity compared with the PEDOT film. It has been already mentioned that, in general, the real impedance of an electrode material also decreases as the material's porosity increases due to improved ionic accessibility [20]-[27] [32]-[41].

Figure 10 shows the SEM images of the PEDOT film. In Figure 10(a), a nodular accumulating structure is evidenced. The size of the nodules ranged a few hundred nanometers in diameter and they aggregate to form gobbets. In Figure 10(b), the effect of dopant on the morphology of PEDOT film can be observed: lamellar 


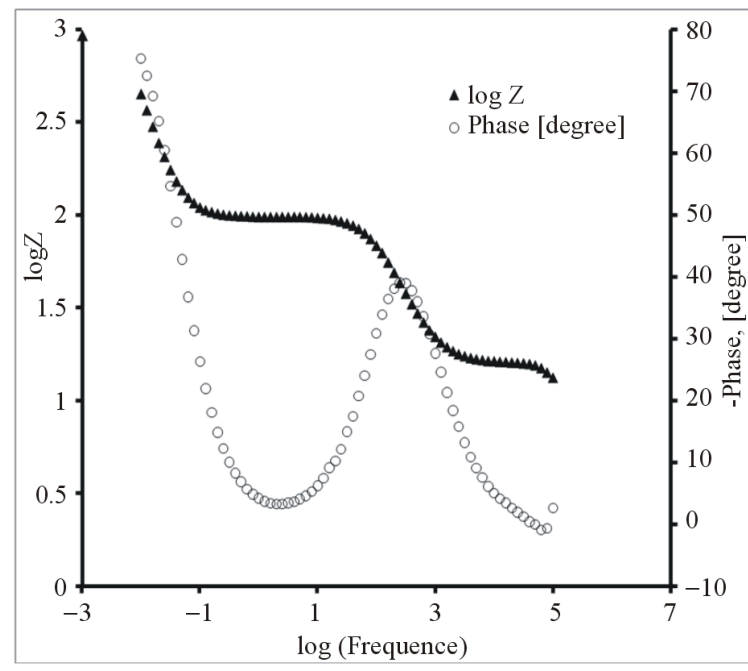

(a)

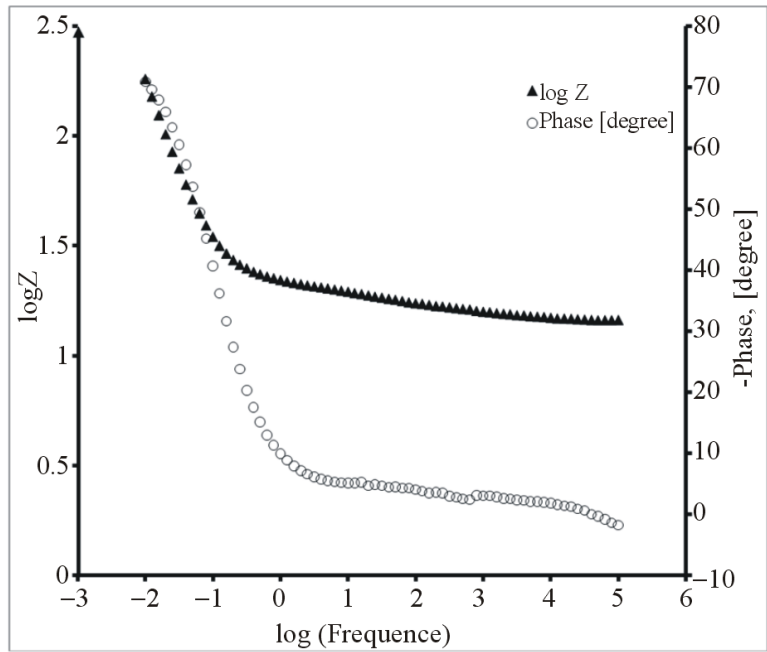

(c)

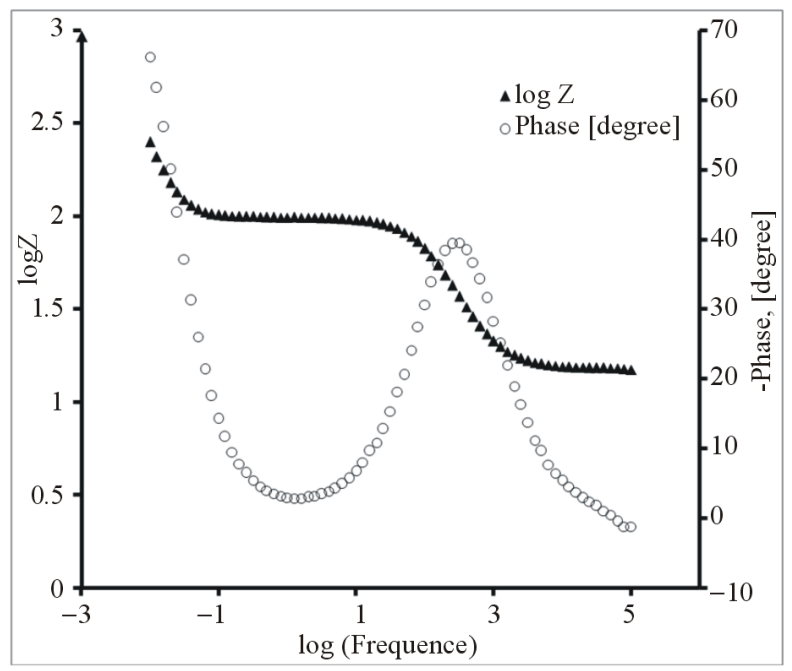

(b)

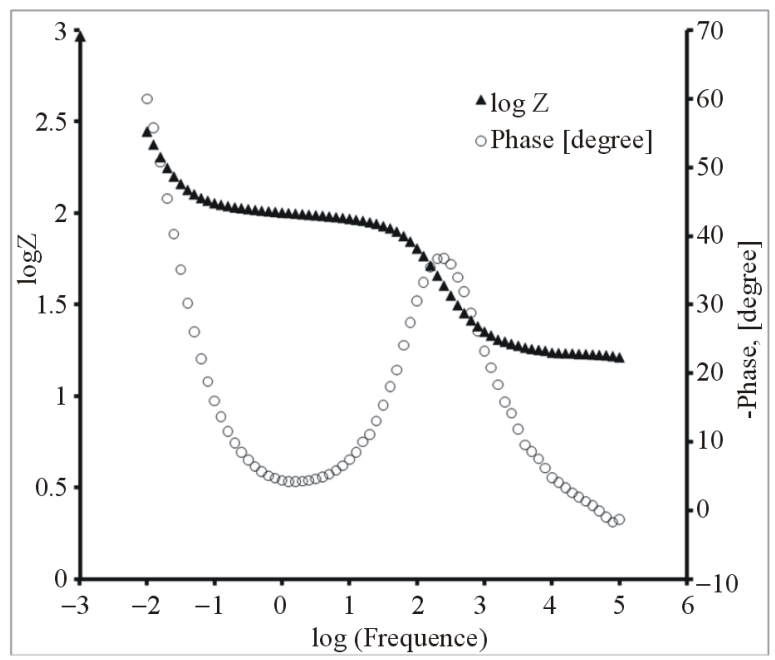

(d)

Figure 8. The Bode diagrams for modified electrodes (a) PEDOT/Pt, (b) PEDOT/CNTs-COOH/Pt, (c) PEDOT/CNTs$\mathrm{COOH} / \mathrm{SDS} / \mathrm{Pt}$ and (d) PEDOT/CNTs-COOH/tiron/Pt at open circuit potential in an aqueous solution of $0.1 \mathrm{M} \mathrm{LiClO}_{4}$.

Table 1. Real impedance and capacitance values of pure PEDOT film and PEDO/FSWCNTs nanocomposite film with different dopants obtained by co-polymerization using the cyclic voltammetry (CV) at $0.01 \mathrm{~Hz}$.

\begin{tabular}{cccc}
\hline Polymeric film & $\begin{array}{c}\text { Slope values obtained from graph } \\
-Z^{\prime}=\mathrm{f}(1 / 2 \pi \mathrm{f})\end{array}$ & $\begin{array}{c}\mathrm{C} \\
{\left[\mathrm{F} / \mathrm{cm}^{2}\right]}\end{array}$ & $\mathrm{Z}_{\mathrm{r}}\left(\Omega \mathrm{cm}^{2}\right)$ at $0.01 \mathrm{~Hz}$ \\
\hline PEDOT & 103 & 0.009 & 357 \\
PEDOT/CNT-COOH & 72 & 0.014 & 267 \\
PEDOT/CNT-COOH/SDS & 15 & 0.067 & 120 \\
PEDOT/CNT-COOH/tiron & 11 & 0.091 & 139 \\
\hline
\end{tabular}

structure with almost vertical orientation to the substrate. It is evident that dopant changes the morphology of PEDOT film into a more porous structure with higher interface area. This is in agreement with the SEM results presented below that illustrated a smaller porosity in the PEDOT film than in the case of the composite film with dopant. The SEM images showed that nanocomposite films were more porous than PEDOT films.

Fourier transform infrared (FT-IR see Figure 11) spectra were carried with a Bruker optics spectrometer at room temperature. All spectra in this paper were obtained at a resolution $4 \mathrm{~cm}^{-1}$ in the region $4000-600 \mathrm{~cm}^{-1}$. 


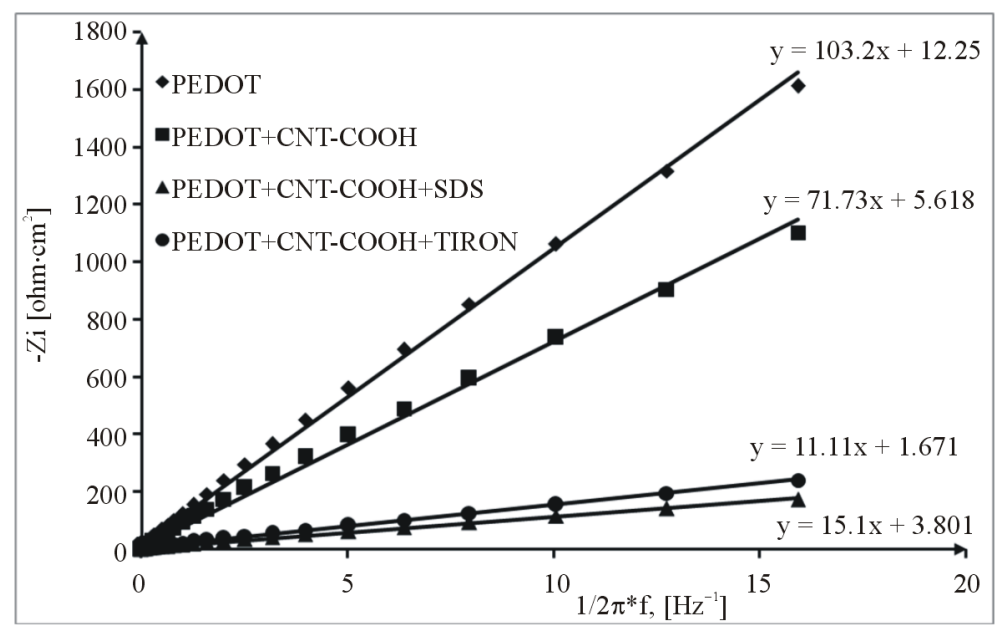

Figure 9. Capacitance evaluation for PEDOT/Pt, PEDOT/CNT/Pt, PEDOT/ CNT-COOH/SDS/Pt and PEDOT/CNT-COOH/ tiron/Pt modified electrode.

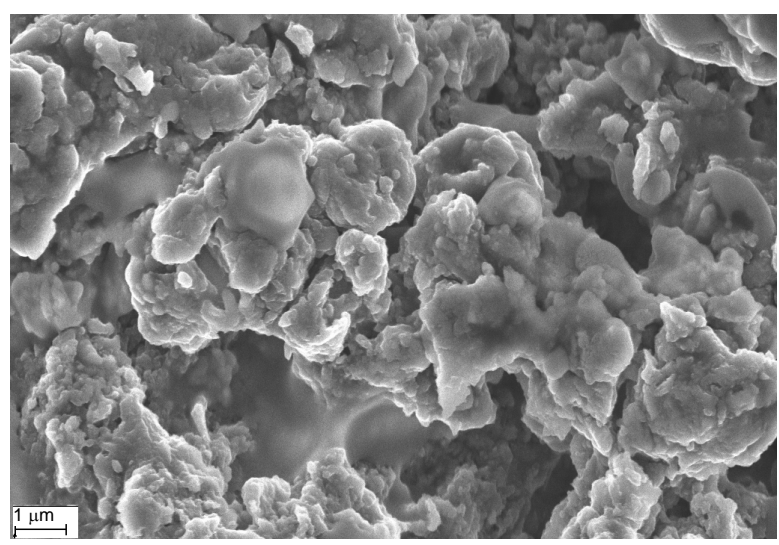

(a)

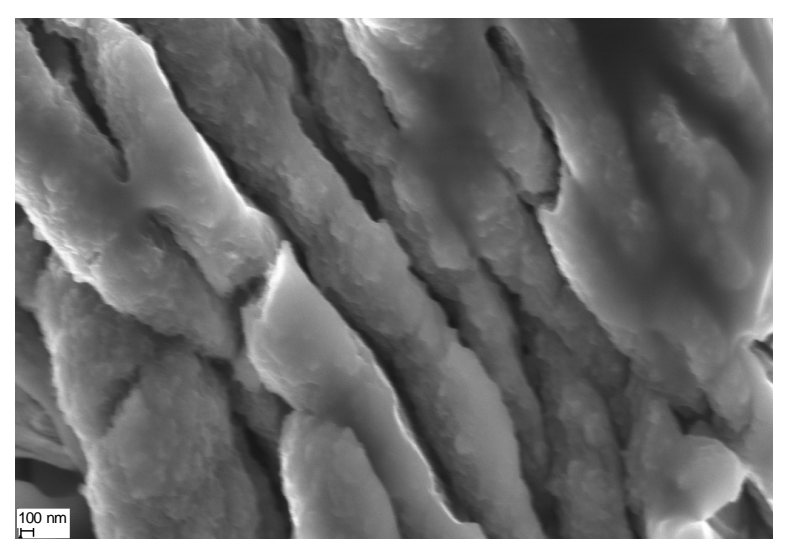

(b)

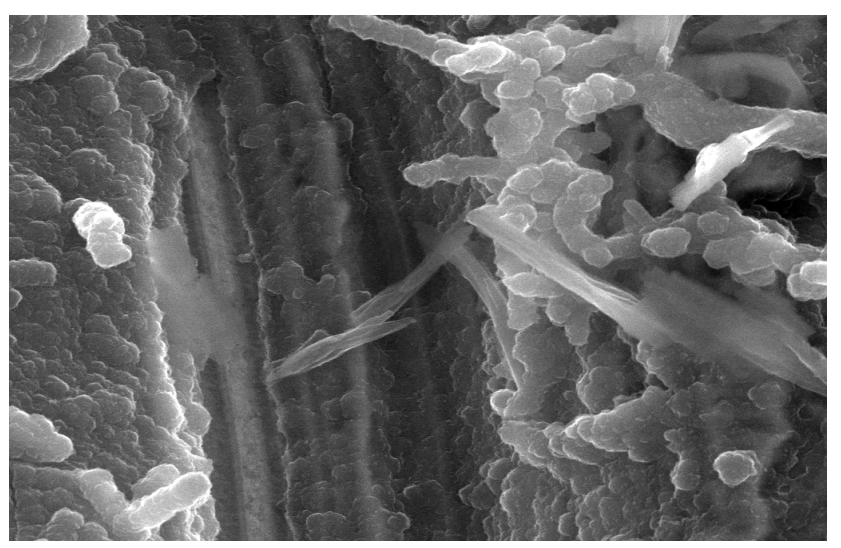

(c)

Figure 10. SEM images of the film surface of (a) PEDOT and (b) PEDOT doped film formation by cyclic voltammetry (0 to $1250 \mathrm{mV}$ at a scan rate of $10 \mathrm{mV} / \mathrm{s}$ ), (c) PEDOT/CNT-COOH.

FT-IR spectrometer is a powerful instrument that can be used to determine type of bonding for to obtain a new composite. The characteristic bands in the FT-IR spectrum for PEDOT and nanocomposite are the following: a very weak and a medium band at $3000-4000 \mathrm{~cm}^{-1}$ is assigned to the C-H and $\mathrm{OH}$ stretching modes; vibration at 1521, 1476, 1328 and $922 \mathrm{~cm}^{-1}$ for PEDOT+ nanocompozit and 1501, 1403, 1181 and $916 \mathrm{~cm}^{-1}$ for PEDOT are 


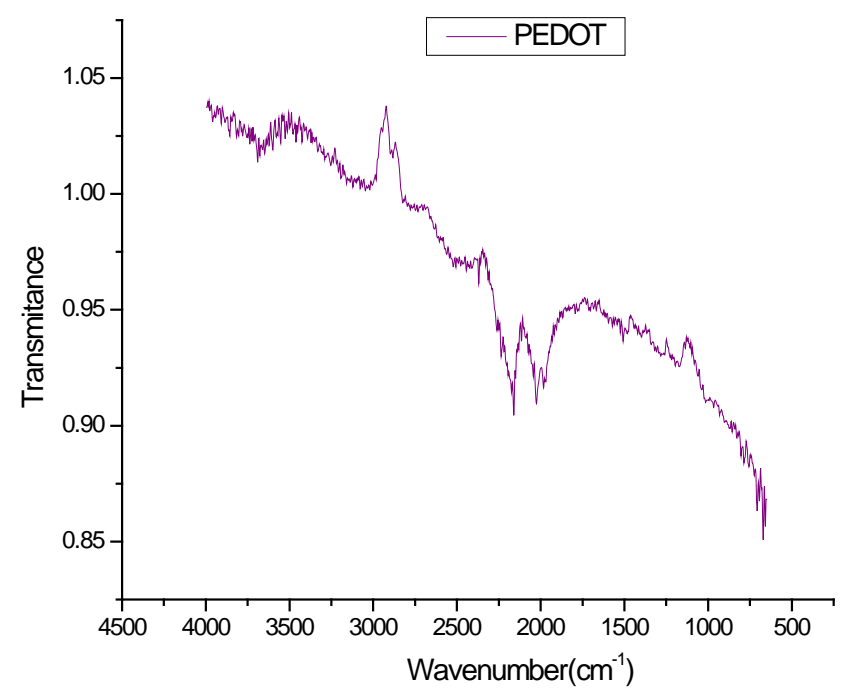

(a)

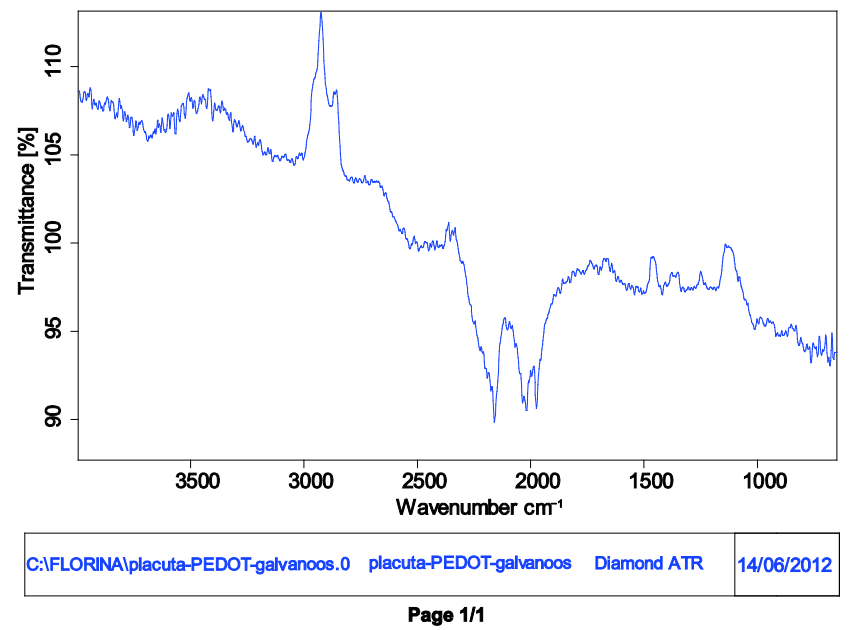

(b)

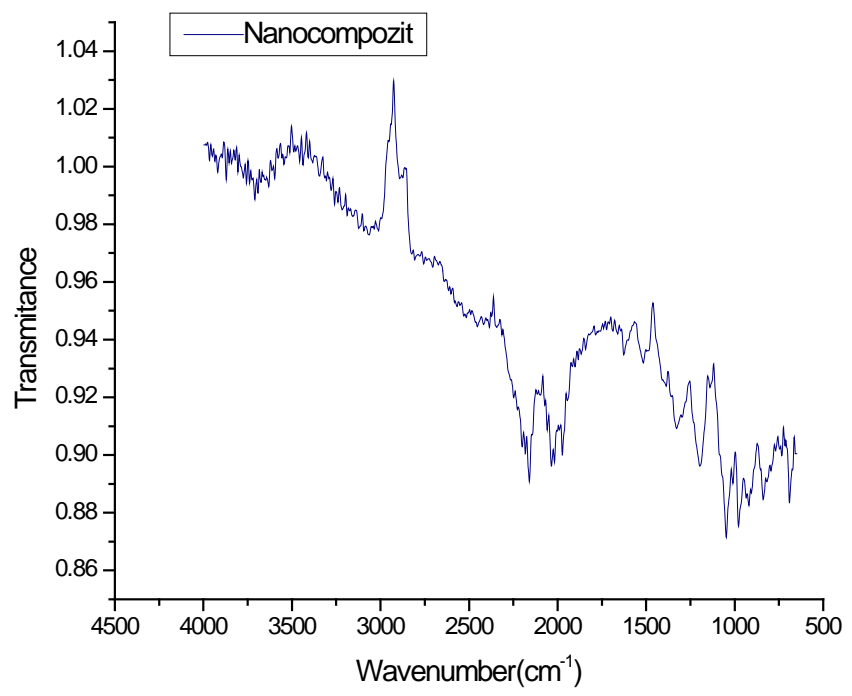

(c)

Figure 11. FT-IR spectra of PEDOT and nanocompozit. 
attributed to the stretching modes of C=C, C-C, and C-S in the thiophene ring [40] [42]-[44]. The bands at 1203 and $1046 \mathrm{~cm}^{-1}$ are assigned to the stretching modes of the ethylenedioxy (alkylenedioxy) group and the band around 1046 and $922 \mathrm{~cm}^{-1}$ is due to the ethylenedioxy ring deformation mode. The spectrum shows several bands of which the band at $822 \mathrm{~cm}^{-1}$ for nanocompozit and $815 \mathrm{~cm}^{-1}$ for PEDOT is assigned to the symmetric C-S-C deformation. The band at $1046 \mathrm{~cm}^{-1}$ (nanocompozit) and $1412 \mathrm{~cm}^{-1}$ (PEDOT) is assigned to the symmetric C-O-C ether bond. A difference that can be observed is the intensity ratio of bands the spectrum (1500 $600 \mathrm{~cm}^{-1}$ ) of nanocompozit film than PEDOT band, exhibits a clear difference in intensity [45]. This may suggest that the dopant promotes and stabilizes the structure of the film (nanocomposite).

\section{Conclusions}

Electrochemically synthesized composite films of conducting polymers (PEDOT) and FSWCNTs with different dopants have in common a porous structure at nano-meter scales. They have better mechanical integrity and a higher conductivity than the similarly prepared pure polymer. The electrochemical activity of PEDOT/FSWCNTs/Pt modified electrode in $0.1 \mathrm{M} \mathrm{LiClO}_{4}$ cycling solution is much more higher than of PANI/Pt modified electrode in the same cycling solution.

The Nyquist plots for both PEDOT and composite films are featured by a vertical trend at low frequencies, indicating a capacitive behaviour according to the equivalent circuit theory. The higher capacitance of the composite films results obviously from the contribution of the embedded FSWCNTs that provide interconnected pathways for electrons through the FSWCNTs and ions through the pore network or the direct interaction between the delocalised electrons on polymer chains and the FSWCNTs.

The PEDOT and FSWCNTsF with dopants films reveal a morphological structure composed of nanofibers, but for the pure polymeric ones they are slightly thicker than those in the PANI/FSWCNTs composite film.

Microstructures of these composites suggests that PEDOT was wrapped around FSWCNTs. The obtained results can be employed to get the desired value of the capacitance by choosing the adequate preparation method and so, by controlling the microstructure of the composites.

\section{Acknowledgements}

Financial support from PN-II-ID-PCE-2008-2 contract number 596, code ID_716 (The National University Research Council) is gratefully acknowledged.

\section{References}

[1] Ajayan, P.M., Stephan, O., Colliex, C. and Trauth, D. (1994) Aligned Carbon Nanotube Arrays Formed by Cutting a Polymer Resin-Nanotube Composite. Science, 265, 1212-1214. http://dx.doi.org/10.1126/science.265.5176.1212

[2] Dai, L. and Mau, A.W.H. (2001) Controlled Synthesis and Modification of Carbon Nanotubes and $\mathrm{C}_{60}$ : Carbon Nanostructures for Advanced Polymeric Composite Materials. Advanced Materials, 13, 899-913. http://dx.doi.org/10.1002/1521-4095(200107)13:12/13<899::AID-ADMA899>3.0.CO;2-G

[3] Baughman, R.H., Zakhidov, A.A. and Heer, W.A. (2002) Carbon Nanotubes-the Route toward Applications. Science, 297, 787-792. http://dx.doi.org/10.1126/science.1060928

[4] Liao, Y.Z., Zhang, C., Zhang, Y., Strong, V., Tang, J.S., Li, X.-G., Kalantar-Zadeh, K., Hoek, E., Wang, K. and Kaner, R. (2011) Carbon Nanotube/Polyaniline Composite Nanofibers: Facile Synthesis and Chemosensors. Nano Letters, 11, 954-959. http://dx.doi.org/10.1021/nl103322b

[5] Dai, L. (1999) Advanced Syntheses and Microfabrications of Conjugated Polymers, $\mathrm{C}_{60}$-Containing Polymers and Carbon Nanotubes for Optoelectronic Applications. Polymers for Advanced Technologies, 10, 357-420. http://dx.doi.org/10.1002/(SICI)1099-1581(199907)10:7<357::AID-PAT886>3.0.CO;2-9

[6] Chen, G.Z., Shaffer, M.S.P., Coleby, D., Dioxan, G., Fray, D.J. andWindle, A.H. (2000) Carbon Nanotube and Polypyrrole Composites: Coating and Doping. Advanced Materials, 12, 522-526. http://dx.doi.org/10.1002/(SICI)1521-4095(200004)12:7<522::AID-ADMA522>3.0.CO;2-S

[7] Saito, Y., Uemura, S. and Hamaguchi, K. (1998) Cathode Ray Tube Lighting Elements with Carbon Nanotube Field Emitters. Japanese Journal of Applied Physics, 37, L346-L348. http://dx.doi.org/10.1143/JJAP.37.L346

[8] Liao, Y., Zhang, C., Wang, X., Li, X.G., Ippolito, S.J., Kalantar-Zadeh, K. and Kaner, R.B. (2011) Carrier Mobility of 
Single-Walled Carbon Nanotube-Reinforced Polyaniline Nanofibers. The Journal of Physical Chemistry C, 115, 16187-16192. http://dx.doi.org/10.1021/jp2053585

[9] Prună, A., Branzoi, V. and Branzoi, F. (2011) Ordered Arrays of Copper Nanowires Enveloped in Polyaniline Nanotubes. Journal Applied Electrochemistry, 41, 77-81. http://dx.doi.org/10.1007/s10800-010-0209-4

[10] Shirakwa, H. (2001) The Discovery of Polyacetylene Film: The Dawning of an Era of Conducting Polymers (Nobel Lecture). Angewandte Chemie International Edition, 40, 2574-2580. http://dx.doi.org/10.1002/1521-3773(20010716)40:14<2574::AID-ANIE2574>3.0.CO;2-N

[11] Groenendaal, B.L., Jonas, F., Freitag, D., Pielartzik, H. and Reynolds, J.R. (2000) Poly(3,4-Ethylenedioxythiophene) and Its Derivatives: Past, Present, and Future. Advanced Materials, 12, 481-494.

[12] Crispin, X., Jakobsson, F.L.E., Crispin, A., Grim, P.C.M., Andersson, P., Volodin, A., van Haesendonck, C., Van der Auweraer, M., Salaneck, W.R. and Berggren, M. (2006) The Origin of the High Conductivity of Poly(3,4-Ethylenedioxythiophene)-Poly(Styrenesulfonate) (PEDOT-PSS) Plastic Electrodes. Chemistry of Materials, 18, 4354-4360. http://dx.doi.org/10.1021/cm061032+

[13] Breiby, D.W., Samuelsen, L.B. and Groenendaal, B. (2003) Smectic Structures in Electrochemically Prepared Poly(3,4-Ethylenedioxythiophene) Films. Journal of Polymer Science Part B: Polymer Physics, 41, 945-952. http://dx.doi.org/10.1002/polb.10412

[14] Winther-Jensen, B. and West K. (2006) Stability of Highly Conductive Poly-3,4-Ethylene-Dioxythiophene. Reactive and Functional Polymers, 66, 479-483. http://dx.doi.org/10.1016/j.reactfunctpolym.2005.08.007

[15] Kros, A., Sommerdijk, N.A.J.M. and Nolte R.J.M. (2005) Poly(Pyrrole) versus Poly(3,4-Ethylenedioxythiophene): Implications for Biosensor Applications. Sensors and Actuators B: Chemical, 106, 289-295. http://dx.doi.org/10.1016/j.snb.2004.08.011

[16] Luo, S.C., Mohamed Ali, E., Tansil, N.C., Yu, H.H., Gao, S. and Ying, J.Y. (2008) Poly(3,4-ethylenedioxythiophene) (PEDOT) Nanobiointerfaces: Thin, Ultrasmooth, and Functionalized PEDOT Films with in Vitro and in Vivo Biocompatibility. Langmuir, 24, 8071-8077. http://dx.doi.org/10.1021/la800333g

[17] Du, X. and Wang, Z. (2003) Effects of Polymerization Potential on the Properties of Electrosynthesized PEDOT Films. Electrochimica Acta, 48, 1713-1717. http://dx.doi.org/10.1016/S0013-4686(03)00143-9

[18] Li, L., Loveday, D.C., Mudigonda, D.S.K. and Ferraris, J.P. (2002) Effect of Electrolytes on Performance of Electrochemical Capacitors Based on Poly[3-(3,4-difluorophenyl)thiophene]. Journal of the Electrochemical Society, 149, A1201-A1207. http://dx.doi.org/10.1149/1.1498840

[19] Branzoi, V., Prună, A. and Branzoi, F. (2008) Electrosynthesized Doped Polypyrrole Films on Pure Zinc Electrode. Molecular Crystal and Liquid Crystals, 485, 853-861. http://dx.doi.org/10.1080/15421400801922486

[20] Branzoi, V., Branzoi, F. and Pilan, L. (2009) Characterization of Electrodeposited Polymeric and Composite Modified Electrodes on Cobalt Based Alloy. Materials Chemistry and Physics, 118, 197-203. http://dx.doi.org/10.1016/j.matchemphys.2009.07.020

[21] Ago, H., Petritch, K., Shaffer, M.S.P., Windle, A.H. and Friend, R.H. (1999) Composites of Carbon Nanotubes and Conjugated Polymers for Photovoltaic Devices. Advanced Materials, 11, 1281-1285. http://dx.doi.org/10.1002/(SICI)1521-4095(199910)11:15<1281::AID-ADMA1281>3.0.CO;2-6

[22] Hughes, M., Chen, G.Z., Shaffer, M.S., Fray, D.J. and Windle, A.H. (2002) Electrochemical Capacitance of a Nanoporous Composite of Carbon Nanotubes and Polypyrrole. Chemistry of Materials, 14, 1610-1613.

[23] Downs, C., Nuget, J., Ajayan, P.M., Duquette, D.J. and Santhanam, K.S.V. (1999) Growth from Surface Methodology for the Fabrication of Functional Dual Phase Conducting Polymer Polypyrrole/Polycarbazole/Polythiophene (cp/Polypyr/ Polycbz/Polyth)-Carbon Nanotube (cnt) Composites of Controlled Morphology and Composition—Sidewall Vers. Advanced Materials, 12, 1028.

[24] Peng, C., Jin, J. and Chen, G.Z. (2007) A Comparative Study on Electrochemical Co-Deposition and Capacitance of Composite Films of Conducting Polymers and Carbon Nanotubes. Electrochimica Acta, 53, 525-537. http://dx.doi.org/10.1016/j.electacta.2007.07.004

[25] Wang, J., Dai, J. and Yarlagadda, T. (2005) Carbon Nanotube-Conducting-Polymer Composite Nanowires. Langmuir, 21, 9-12. http://dx.doi.org/10.1021/la0475977

[26] Tsai, Y.C., Li, S.C. and Liao, S.W. (2006) Electrodeposition of Polypyrrole-Multiwalled Carbon Nanotube-Glucose Oxidase Nanobiocomposite Film for the Detection of Glucose. Biosensors and Bioelectronics, 22, 495-500. http://dx.doi.org/10.1016/j.bios.2006.06.009

[27] Chen, J., Hamon, M.A., Hu, H., Chen, Y., Rao, A.M., Eklund, P.C. and Haddon, R.C. (1998) Solution Properties of Single-Walled Carbon Nanotubes. Science, 282, 95-98. http://dx.doi.org/10.1126/science.282.5386.95

[28] Chen, Y., Haddon, R.C., Fang, S., Rao, A.M., Eklund, P.C., Lee, W.H., Dickey, E.C., Grulke, E.A., Pendergrass, J.C., 
Chavan, A., Haley, B.E. and Smalley, R.E. (1998) Chemical Attachment of Organic Functional Groups to SingleWalled Carbon Nanotube Material. Journal of Materials Research, 13, 2423-2431. http://dx.doi.org/10.1557/JMR.1998.0337

[29] Holzinger, M., Vostrowsky, O., Hirsch, A., Hennrich, F., Kappes, M., Weiss, R. and Jellen, F. (2001) Sidewall Functionalization of Carbon Nanotubes. Angewandte Chemie International Edition, 40, 4002-4005. http://dx.doi.org/10.1002/1521-3773(20011105)40:21<4002::AID-ANIE4002>3.0.CO;2-8

[30] Dyke, C.A. and Tour, J.M. (2003) Unbundled and Highly Functionalized Carbon Nanotubes from Aqueous Reactions. Nano Letters, 3, 1215-1218. http://dx.doi.org/10.1021/nl034537x

[31] Saini, R.K., Chiang, I.W., Peng, H., Smalley, R.E., Billups, W.E., Hauge, R.H. and Margrave, J.L. (2003) Covalent Sidewall Functionalization of Single Wall Carbon Nanotubes. Journal of the American Chemical Society, 125, 36173621. http://dx.doi.org/10.1021/ja021167q

[32] Dyke, C.A. and Tour, J.M. (2003) Solvent-Free Functionalization of Carbon Nanotubes. Journal of the American Chemical Society, 125, 1156-1157. http://dx.doi.org/10.1021/ja0289806

[33] Williams, K.A., Veenhuizen, P.T.M., de la Torre, B.G., Eritja, R. and Dekker, C. (2002) Nanotechnology: Carbon Nanotubes with DNA Recognition. Nature, 420, 761. http://dx.doi.org/10.1038/420761a

[34] Niyogi, S., Hamon, M.A., Hu, H., Zhao, B., Bhowmik, P., Sen, R., Itkis, M.E. and Haddon, R.C. (2002) Chemistry of Single-Walled Carbon Nanotubes. Accounts of Chemical Research, 35, 1105-1113. http://dx.doi.org/10.1021/ar010155r

[35] Kamaras, K., Itkis, M.E., Hu, H., Zhao, B. and Haddon, R.C. (2003) Covalent Bond Formation to a Carbon Nanotube Metal. Science, 301, 1501. http://dx.doi.org/10.1126/science.1088083

[36] Chen, J., Rao, A.M., Lyuksyutov, S., Itkis, M.E., Hamon, M.A., Hu, H., Cohn, R.W., Eklund, P.W., Colbert, D.T., Smalley, R.E. and Haddon, R.C. (2001) Dissolution of Full-Length Single-Walled Carbon Nanotubes. Journal of Physical Chemistry B, 105, 2525-2528. http://dx.doi.org/10.1021/jp002596i

[37] Zhao, B., Hu, H. and Haddon, R.C. (2004) Synthesis and Properties of a Water-Soluble Single-Walled Carbon Nanotube-Poly(m-aminobenzene sulfonic acid) Graft Copolymer. Advanced Functional Materials, 14, 71-76. http://dx.doi.org/10.1002/adfm.200304440

[38] Jurewiez, K., Delpeux, S., Bertagna, V., Beguin, F. and Frackowiak, E. (2001) Supercapacitors from Nanotubes/Polypyrrole Composites. Chemical Physics Letters, 347, 36-40. http://dx.doi.org/10.1016/S0009-2614(01)01037-5

[39] Gupta, V. and Miura, N. (2006) Polyaniline/Single-Wall Carbon Nanotube (PANI/SWCNT) Composites for High Performance Supercapacitors. Electrochimica Acta, 52, 1721-1726. http://dx.doi.org/10.1016/j.electacta.2006.01.074

[40] Xiao, Q. and Zhou, X. (2003) The Study of Multiwalled Carbon Nanotube Deposited with Conducting Polymer for Supercapacitor. Electrochimica Acta, 48, 575-580. http://dx.doi.org/10.1016/S0013-4686(02)00727-2

[41] Zeng, J.X., Wei, W.Z., Wu, L., Liu, X.Y., Liu, K. and Li, Y. (2006) Fabrication of Poly(toluidine blue O)/Carbon Nanotube Composite Nanowires and Its Stable Low-Potential Detection of NADH. Journal of Electroanalytical Chemistry, 595, 152-160. http://dx.doi.org/10.1016/j.jelechem.2006.07.014

[42] Ferrer-Anglada, N., Kaempgen, M. and Roth, S. (2006) Transparent and Flexible Carbon Nanotube/Polypyrrole and Carbon Nanotube/Polyaniline pH Sensors. Physica Status Solidi (b), 243, 3519-3523. http://dx.doi.org/10.1002/pssb.200669220

[43] Santhosh, P., Manesh, K.M., Lee, K.P. and Gopalan, A.I. (2006) Enhanced Electrocatalysis for the Reduction of Hydrogen Peroxide at New Multiwall Carbon Nanotube Grafted Polydiphenylamine Modified Electrode. Electroanalysis, 18, 894-903. http://dx.doi.org/10.1002/elan.200503474

[44] Lu, G.W., Li, C., Shen, J.Y., Chen, Z.J. and Shi, G.Q. (2007) Preparation of Highly Conductive Gold-Poly(3,4-ethylenedioxythiophene) Nanocables and Their Conversion to Poly(3,4-ethylenedioxythiophene) Nanotubes. Journal of Physical Chemistry C, 111, 5926-5931. http://dx.doi.org/10.1021/jp070387t

[45] Ingan, O. (1997) Handbook of Conducting Polymers. Vol. 2, Wiley, New York, 785. 